AURELIA JOURNAL VOL. 3 (1) OKTOBER 2021 : 35-46

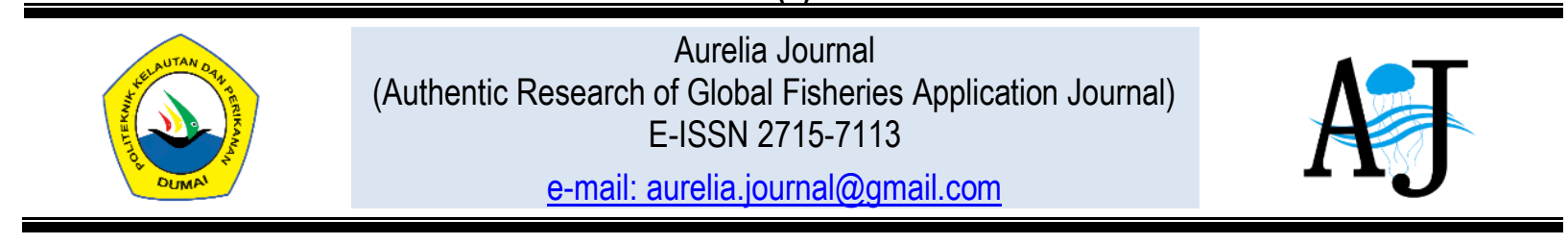

\title{
ANALISA EFISIENSI PENGGUNAAN MESIN LISTRIK KAPAL PENANGKAP IKAN STUDI KASUS PADA KM. PULAU PINANG
}

\section{EFFICIENCY ANALYSIS OF USING FISHING VESSEL'S ELECTRIC ENGINE CASE STUDY IN MV. PINANG ISLAND}

\author{
Hafiz Ziddin ${ }^{1}$, Bobby Demeianto ${ }^{1 *}$, Juniawan Preston Siahaan ${ }^{1}$ \\ ${ }_{1}^{1}$ Program Studi Permesinan Kapal, Politeknik Kelautan dan Perikanan Dumai, Dumai, Indonesia \\ *Korespondensi: bobby.demeianto@gmail.com (B Demeianto) \\ Diterima 19 Agustus 2021 - Disetujui 20 September 2021
}

\begin{abstract}
ABSTRAK. Energi listrik kapal perikanan Pukat Cincin di hasilkan dari Generator Set. Dimana, Kebutuhan daya beban listrik yang berhubungan dengan kapasitas dari Generator harus memiliki nilai efisiensi dari $78 \%$ atau sampai dengan $100 \%$. Bertujuan agar tidak terjadi kerugian secara ekonomis. Serta peninjauan kecepatan putaran mesin penggerak Generator yang harus sesuai. Maka dari itu, penelitian ini dalam Perhitungan nilai efisiensi penggunaan Generator dan Putaran mesin penggerak Generator. Selanjutnya, menentukan Evaluasi nilai efisiensi penggunaan Generator di KM. Pulau Pinang. Peninjauan langsung di lapangan dengan cara pengukuran nilai tegangan, daya, dan arus listrik di KM. Pulau Pinang hal ini merupakan metode penelitian. Nilai daya tertinggi pada Motor pompa. Pemakaian daya listrik secara keseluruhan permasing masing unit nilai tertinggi terdapat pada lampu Halogen. Nilai teganagan 3 fasa dan arus listrik nilai rata rata terendah dan tertinggi adalah 310,33 Volt 11,33 A dan 316,33 Volt 23,47 A, dan kecepatan putaran mesin penggerak Generator yaitu 1.121,5 rpm. Selanjutnya, Nilai efisiensi daya aktif terhitung adalah $42,142 \%$, di rekomendasikan kapasitas Generator 30 kVA. Rpm pengoperasian mesin listrik di simpulkan lebih kecil dari rpm spesifikasi mesin penggerak generator. Dengan catatan rpm mesin penggerak generator tidak melebihi spesifikasi rpm generator $(2.800 \mathrm{rpm} \leq 1.500 \mathrm{rpm})$.
\end{abstract}

KATA KUNCI: Efisiensi, listrik kapal penangkap ikan, putaran mesin

ABSTRACT. The electric energy of the purse seine fishing vessel is generated from the Generator Set. Where, the need for electrical load related to the capacity of the generator must have an efficiency value of $78 \%$ or up to $100 \%$. The aim is to avoid economic losses. As well as reviewing the rotational speed of the generator driving engine which must be appropriate. Therefore, this research is in the calculation of the efficiency value of the use of the generator and the engine rotation of the generator. Next, determine the evaluation of the efficiency value of using generators in MV. Pinang Pinang. Direct observation in the field by measuring the value of voltage, power, and electric current in MV. Pinang Pinang this is a research method. The highest rated power on the pump motor. The overall electrical power consumption per each unit is the highest value found in Halogen lamps. The value of 3-phase voltage and electric current the lowest and highest average values are 310.33 Volts $11.33 \mathrm{~A}$ and 316.33 Volts $23.47 \mathrm{~A}$, and the rotational speed of the generator driving engine is 1,121.5 rpm. Furthermore, the calculated active power efficiency value is $42.142 \%$, the recommended generator capacity is $30 \mathrm{kVA}$. The operating rpm of the electric engine is concluded to be smaller than the rpm specification of the engine driving the generator. With a note that the engine rpm of the generator does not exceed the specifications of the generator rpm $(2,800 \mathrm{rpm}$ $1,500 \mathrm{rpm})$.

KEYWORDS: Efficiency, fishing vessel electricity, engine's rotation

\section{Pendahuluan}

Kapal Perikanan Pukat cincin adalah kapal penangkap ikan yang mengunakan alat tangkap Pukat Cincin (Pusre Seine), yang dioperasikan dengan cara melingkari gerombolan ikan hingga alat berbentuk seperti mangkuk pada akhir proses penangkapan ikan yang bergerombol (Nur, Farid, \& Apri Arisandi, 2009). Salah satu sistem penunjang kerja utama di kapal adalah sistem kelistrikan yang secara umum terdiri dari sumber daya, sistem distribusi, dan peralatan kelistrikan. Daya listrik yang tersedia digunakan untuk memenuhi kebutuhan penerangan, peralatan navigasi, dan komunikasi, sistem alarm dan monitoring, 
pengaturan udara dan sistem refrigrasi, motor pompa dan permesinan dek hingga propulsi (Fahrurozi,Firdaus,\& Feranita., 2014).

Energi listrik kapal perikanan Pukat Cincin di hasilkan dari Generator Set. Dimana, putaran pada Generator di salurkan oleh putaran dari mesin diesel yang menggunakan bahan bakar solar. Diketahui, keluaran dari Generator adalah tengagan, daya, dan arus listrik. Dimana, mempengaruhi faktor dari nilai Daya Semu dan Daya aktif. Kebutuhan daya beban listrik yang berhubungan dengan kapasitas dari Generator harus memiliki nilai efisiensi dari $78 \%$ atau sampai dengan $100 \%$. Bertujuan agar tidak terjadi kerugian secara ekonomis serta peninjauan kecepatan putaran mesin penggerak Generator. Meninjau hal tersebut, penelitian kali ini bertujuan agar memperoleh indentifikasi efisiensi penggunaan Generator.

Generator Set adalah sebuah perangkat yang berfungsi menghasilakan daya listrik. Disebut sebagai Generator Set dikarenakan suatu set peralatan gabungan dari dua perangkat berbeda yaitu mesin dan Generator atau alternator. Mesin (Engine) sebagai perangkat pemutar sedangkan Generator atau alternator sebagai perangkat pembangkit listrik. Engine dapat berupa perangkat mesin disel berbahan bakar solar, mesin berbahan bakar bensin, mesin gas, maupun mesin turbin. Ada bermacam macam mesin sesuai dengan kebutuhan. Sedangkan Generator atau alternator merupakan kumparan atau gulungan tembaga yang terdiri dari stator (kumparan statis) dan rotor (kumparan berputar). Pada hakikatnya, sebuah mesin digunakan untuk memutar sebuah Generator pembangkit yang terbuat dari sekumpulan kawat tembaga. Hasil putaran tersebut menghasilkan medan magnet yang apabila diputar terus menerus dalam suatu kecepatan yang konstan dan berkelanjutan akan menghasilakan arus listrik. Dalam ilmu fisika yang sederhana dapat dijelaskkan bahwa engine memutar rotor pada Generator sehingga timbul medan magnit pada kumparan stator Generator, medan magnit yang timbul pada stator dan berinteraksi dengan rotor yang berputar akan menghasilkan arus listrik sesuai hukum Lorentz (Badaruddin \& Hardiansyah, 2015).

Penentuan kapasitas maupun dimensi generator harus disesuaikan dengan kebutuhan, tidak boleh terlalu kecil kapasitasnya dan tidak boleh terlalu besar dalam dimensinya. Oleh karena itu, sistem instalasi yang dibutuhkan tinjauan dari segi keamanan, dan keselamatan awak kapal dan kondisi teknis kapal. Beberapa kejadian kecelakaan kapal yang disebabkan oleh hubungan singkat listrik pada kapal yang mengabaikan peraturan instalasi umum listrik (PUIL) (Ridwan, 2015).

\section{Metodologi Penelitian}

Pengambilan data penelitian dilaksanakan di atas kapal perikanan KM. Pulau Pinang dari pihak Pelabuhan Perikanan Nusantara Sibolga dan daerah pengoperasian di wilayah perairan Samudera Hindia. Metode pengukuran pada penelitian ini yaitu dengan melakukan pengukuran nilai tegangan listrik dan arus listrik setiap fasa pada panel utama menggunakan tang ampare (clamp meter) pada periodik tertentu saat generator listrik KM. Pulau Pinang melakukan operasi penangkapan ikan atau kegiatan di atas kapal. Pengukuran dilakukan selama 3 hari dengan rentang waktu dari pukul 18:00 sampai dengan 05:00. Pengambilan data penelitian pada indentifikasi aliran listrik yang di ambil berupa nilai tegangan listrik, nilai arus listri, nilai, dan komponen listrik yang digunakan. Pengumpulan data dimaksud untuk mengetahui nilai daya yang terhitung.

Daya listrik atau dalam bahasa Inggris disebut dengan Elektrikal Power adalah jumlah energi yang diserap atau dihasilkan dalam sebuah sirkuit/rangkaian. Sumber energi seperti tegangan listrik akan menghasilkan daya listrik sedangkan beban yang terhubung dengannya akan menyerap daya listrik tersebut. Dengan tiga macam perbedaan yaitu daya aktif, daya reaktif, dan daya semu (Weedy, Cory, Jenkins, Ekanayake, \& Strbac, 2012).

Daya aktif (Active Power) adalah daya yang terpakai untuk melakukan energi sebenarnya. Satuan daya aktif adalah Watt. Berikut rumus persamaan daya aktif $(P)$ :
$P=V . I . \operatorname{Cos} \phi$
(1 Fasa)
Persamaan 1
$P=\sqrt{ } 3 . V \cdot I . \operatorname{Cos} \phi$
(3 Fasa)
Persamaan 2 
Daya semu (Apparent Power) adalah daya yang dihasilkan oleh perkalian antara tegangan efektif dan arus efektif dalam suatu jaringan atau daya yang merupakan hasil penjumlahan trigonometri daya aktif dan daya reaktif. Satuan daya nyata adalah VA.

$\begin{array}{lll}\mathrm{S} & =\text { V.I } & \text { (1 Fasa) } \\ \mathrm{S} & =\sqrt{3} . \mathrm{V} . \mathrm{I} & \text { (3 Fasa) } \\ \text { Ket: } & & \\ \mathrm{P} & =\text { Daya Aktif } & \text { (Watt) } \\ \mathrm{S} & =\text { Daya Semu } & \text { (VoltAmpere) } \\ \mathrm{V} & =\text { Tegangan } & \text { (Volt) } \\ \mathrm{I} & =\text { AruS } & \text { (Ampere) } \\ \text { Cos } \phi & =\text { Faktor Daya } & \end{array}$

Persamaan 3

Persamaan 4

Menurut Fang Lin Lou et al., (2005) setiap energi listrik tidak mungkin terkirim sempurna pada pusat beban. Hal itu dikarenakan ada hilangnya beban yangdisebabkan oleh beberapa hal baik itu dari penghantar ataupun dari beban itu sendiri proses tersebut merupakan sifat alami sehingga dikemukakan konsep efisiensi (daya guna). Untuk mengetahui nilai biaya yang dibutuhkan dapat dihitung menggunakan rumus sebagai berikut:

$$
\begin{aligned}
& \text { Efisiensi }(\eta)=\frac{\text { power output }}{\text { power } \text { Input }} \times 100 \% \\
& \text { Efisiensi }(\eta)=\frac{\text { Daya Guna }}{\text { Daya } \text { Total }} \times 100 \%
\end{aligned}
$$

Persamaan 5

Persamaan 6

Menurut Peri, (2020) menyatakan bahwa dalam suatu sistem ketenaga listrikan yang berkaitan dengan Generator terdapat istilah frekuensi listrik. Frekuensi listrik yang dimaksud tidak hanya didefinisikan sebagai jumlah getaran per detik saja namun dalam kelistrikan didefinisikan sebagai jumlah putaran per detik atau cycle per second:

$$
\begin{array}{lll}
\text { Ns } & =\frac{120 x f}{p} & \\
\text { Ket: } & & \\
\text { Ns } & =\text { Putaran } \quad(\mathrm{rpm}) \\
\text { F } & =\text { Frekuensi } \quad(\mathrm{Hz}) \\
\text { p } & =\text { Jumlah Kutup }
\end{array}
$$$$
\text { Persamaan } 7
$$

Karakteristik motor AC membutukan tegangan input secara proporsional setiap kali terjadi perubahan frekuensi untuk memberikan nilai torsi. Sebagai contoh, jika sebuah mesin di rancang untuk beroperasi pada 460 Volt pada $60 \mathrm{~Hz}$, tegangan yang diberikan harus di kurangi menjadi 230 Volt Ketika frekuensi dikurangi sampai $30 \mathrm{~Hz}$. Dengan demikian rasio volt per hertz harus di atur ke nilai $(430 / 60=$ $7,67 \mathrm{~V} / \mathrm{Hz})($ Nahar, 2010).

\section{Hasil dan Pembahasan}

Generator sinkron (alternator) adalah mesin listrik yang digunakan untuk mengubah energi mekanik menjadi energi listrik dengan perantara induksi medan magnet. Dikatakan Generator sinkron karena jumlah putaran rotor sama dengan jumlah putaran medan magnet pada stator. Generator sinkron mengkonversikan energi mekanik menjadi energi listrik. Tegangan output dari Generator sinkron adalah tegangan bolak-balik, karena itu Generator sinkron disebut juga Generator AC. Pada Generator sinkron, konstruksi sebaliknya, yaitu kumparan jangkar disebut juga kumparan stator karena berada pada tempat 
yang tetap, sedangkan kumparan rotor bersama-sama dengan kutub magnet diputar oleh tenaga mekanik (Azhar \& Syaipul, 2020).

Generator pada kapal KM. Pulau Pinang dengan penggerak yaitu menggunakan mesin diesel. Penggunaan mesin diesel menghasilkan gerak putaran dari gerak naik turun yang dihasilkan piston. Dari data yang di dapat, berikut spesifikasi mesin listrik KM. Pulau Pinang:

Tabel 1. Spesifikasi Mesin listrik KM. Pulau Pinang.

\begin{tabular}{|c|c|c|}
\hline No & Nama Bagian & Spesifikasi \\
\hline 1 & Tegangan & 400 Volt \\
\hline 2 & Daya & $50 \mathrm{Kw}$ \\
\hline 3 & Frekuensi & $50 \mathrm{~Hz}$ \\
\hline 4 & Fasa & 3 Fasa \\
\hline 5 & Jenis Generator & AC (Sinkron) \\
\hline 6 & Mesin Penggerak & Motor Diesel \\
\hline 7 & Merk/model Mesin & Mitsubishi 6D16T \\
\hline 8 & Jumlah Silinder/Daya Mesin & 6/225 HP @2800 Rpm \\
\hline 9 & Volume Silinder (Displacement) & $7.545 \mathrm{cc}$ \\
\hline 10 & Bore $x$ Stroke & $188 \times 115 \mathrm{~mm}$ \\
\hline 11 & Urutan penyemprotan bahan bakar (Firing Order) & $1-5-3-6-2-4$ \\
\hline 12 & Pelumas & Sump basah \\
\hline 13 & Bahan Bakar & Solar \\
\hline
\end{tabular}

\subsection{Beban listrik Pada KM. Pulau Pinang}

Beban listrik menurut spesifikasi masing masing beban pada KM. Pulau Pinang dapat dilihat dari Tabel 2 berikut:

Tabel 2. Beban listrik Pada KM. Pulau Pinang.

\begin{tabular}{clcccl} 
No & Jenis Peralatan listrk & Fasa & $\begin{array}{c}\text { Daya } \\
\text { (Watt) }\end{array}$ & Unit & \multicolumn{1}{c}{ Keterangan } \\
\hline 1 & Lampu Halogen & 1 & 1.000 & 16 & Pemikat lkan \\
2 & Lampu CFL & 1 & 45 & 9 & Penerangan Kapal \\
3 & Lampu CFL & 1 & 36 & 6 & Penerangan Kapal \\
4 & Motor Pompa & 3 & 3.750 & 2 & Kamar mesin \\
5 & Trafo Cas Accu & 1 & 350 & 2 & Kamar mesin \\
6 & Televisi & 1 & 36 & 3 & Kamar ABK, mesin, dan Nakhoda \\
7 & DVD Player & 1 & 15 & 3 & Kamar ABK, mesin, dan Nakhoda \\
8 & Speaker & 1 & 80 & 3 & Kamar ABK, mesin, dan Nakhoda \\
\hline \multicolumn{2}{c}{ Jumlah Daya (Watt) } & & 25.214 & \\
\hline
\end{tabular}

Tabel 2 menujukan nilai daya tertinggi pada Motor pompa. Jumlah motor pompa sebanyak dua akan tetapi tidak di operasikan secara bersamaan. Sesuai dari Single line diagram. Dimana, Motor pompa di fungsikan sebagai motor penggerak pompa air yang di salurkan menuju radiator mesin penggerak Generator. Maka dari itu, untuk perhitungan beban listrik pompa hanya di akumulasikan satu unit.

Pada pemakaian daya listrik secara keseluruhan permasing masing unit nilai tertinggi terdapat pada lampu Halogen. Lampu Halogen di fungsikan sebagai alat penerangan pemikat ikan pada malam hari. 


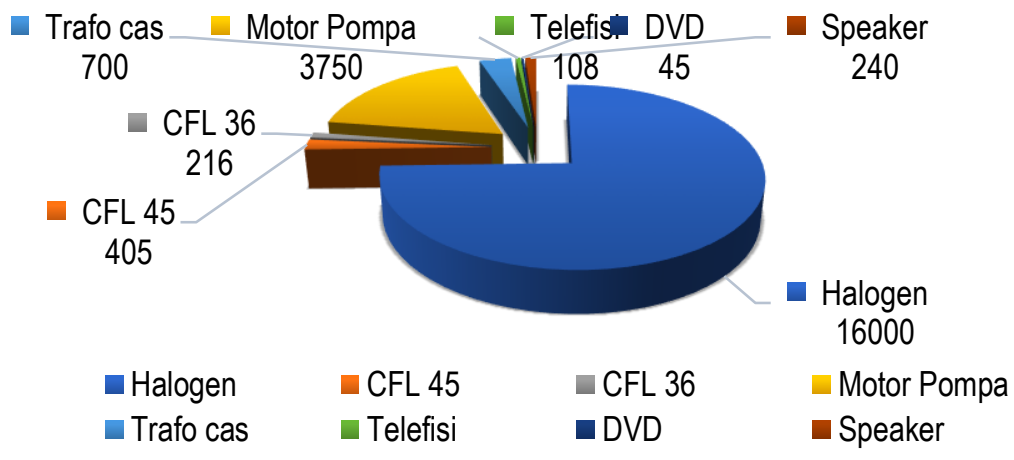

\section{Gambar 1. Pemakaian Beban Listrik.}

\subsection{Pembagian Pemakaian Beban Listrik}

Penambahan beban listrik lampu Halogen ditentukan oleh Nakhoda menurut waktu yang di tentukan. Beban akan bertambah dari jumlah pemakaian tetap lampu Halogen sampai dengan batas jumlah keseluruhan lampu Halogen. Dimana, jumlah beban Halogen keseluruhan di pakai pada jam 05:00.

Jumlah dari lampu Halogen yaitu sebanyak 16 unit. Jadi jika pemakaian beban lampu Halogen terpakai keseluruhan maka akumulasi dari semua pemakaian beban listrik adalah jumlah yang di tunjukan pada tabel 8 di tambah 11.000 watt dan di kurang beban Televisi, DVD, dan Speaker. Dari jam 23:00 sampai dengan 05:00. Maka, nilai yang di dapat pada pemakaian beban listrik adalah 21.071 Watt.

Tabel 3. Perkiraan Pemakaian Beban Listrik dari 18:00 - 05:00.

\begin{tabular}{cccccc}
\hline \multirow{2}{*}{ No } & \multirow{2}{*}{ Jenis Peralatan Listrik } & \multicolumn{4}{c}{ Waktu Pemakaian / Daya Pemakaian (Watt) } \\
\cline { 2 - 6 } & & $\mathbf{1 8 : 0 0 - 2 0 : 0 0}$ & $\mathbf{2 0 : 0 0 - 2 3 : 0 0}$ & $\mathbf{2 3 : 0 0 - 0 2 : 0 0}$ & $\mathbf{0 2 : 0 0 - 0 5 : 0 0}$ \\
\hline 1 & 2 & 3 & 4 & 5 \\
2 & Halogen & 5.000 & 7.000 & 11.000 & 16.000 \\
3 & CFL 45 & 405 & 405 & 405 & 405 \\
4 & CFL 36 & 216 & 216 & 216 & 216 \\
5 & Motor Pompa & 3.750 & 3.750 & 3.750 & 3.750 \\
6 & Trafo cas & 700 & 700 & 700 & 700 \\
7 & Televisi & 108 & 108 & 0 & 0 \\
8 & DVD & 45 & 45 & 0 & 0 \\
\hline & Speaker & 240 & 240 & 0 & 0 \\
\hline
\end{tabular}

Tabel 3 menunjukan jumlah perkiraan beban listrik bertambah pada waku yang di tentukan. Peningkatan jumlah beban listrik terlihat pada lampu Halogen dan penurunan beban listrik terdapat pada Televisi, DVD, dan Speaker di mulai dari jam 23:00 sampai dengan jam 05:00.

\subsection{Idektifikasi Efisiensi Generator}

Nilai daya aktif dan daya semu merupakan faktor memperngaruhi nilai efisiensi penggunaan Generator. Identifikasi efisiensi penggunaan Generator pada KM. Pulau Pinang untuk jumlah pemakaian beban tertinggi di tunjukan pada tabel 4 kolom 5 dapat di buktikan pada persamaan (5) berikut:

Efisiensi $\left(\eta_{G}\right)=\frac{21.071}{50.000} \times 100 \%=42,142 \%$ 
Nilai efisiensi terhitung adalah 42,142\%. Dari nilai tersebut perbandingan kapasitas daya Generator pada KM. Pulau Pinang dan pemakaian daya listrik Generator KM. Pulau Pinang terbilang tidak efisien. Karena, efesiesi yang baik terhitung pada nilai terendah $78 \%$ dan atantara sampai dengan tertinggi 100\%. (Arifin \& Rangga, 2018). Oleh karena itu, di rekomendasikan kapasitas Generator 30 kVA. Terbukti pada perhitungan berikut:

Efisiensi $\left(\eta_{G}\right)=\frac{21.071}{30.000 \times 0,8} \times 100 \%=88 \%$

\subsection{Nilai Efisiensi Generator Terhadap Profil Daya Semu}

Pengoperasian mesin listrik pada KM. Pulau Pinang di muali dari jam 18:00 sampai dengan 05:00 hal tersebut berhubungan dengan tujuan penggunaan mesin listrik yaitu sebagai alat penerangan. Dibuktikan pada gambar 1, bahwa nilai terbesar penggunaan beban listrik terdapat pada lampu Halogen. Berikut profil penggunaan beban listrik pada KM. Pulau Pinang:

Tabel 4. Pengukuran Tegangan dan Arus Listrik 09 Maret 2021.

\begin{tabular}{ccccccccccc}
\multirow{2}{*}{ No } & Waktu & \multicolumn{4}{c}{ Tegangan Listrik (Volt ) } & \multicolumn{3}{c}{ Arus Listrik (Amperee ) } \\
\cline { 3 - 10 } & & R-S & R - T & S - T & R - N & S - N & T - N & R & S & T \\
\hline 1 & 18.00 & 325 & 322 & 323 & 194 & 192 & 192 & 8,73 & 11,04 & 16,65 \\
2 & 19.00 & 323 & 320 & 322 & 193 & 191 & 192 & 8,68 & 10,99 & 16,62 \\
3 & 20.00 & 319 & 316 & 317 & 190 & 188 & 189 & 10,62 & 10,8 & 16,54 \\
4 & 21.00 & 316 & 312 & 317 & 188 & 188 & 188 & 14,11 & 10,98 & 19,4 \\
5 & 22.00 & 317 & 313 & 317 & 189 & 188 & 189 & 13,99 & 10,93 & 19,3 \\
6 & 23.00 & 318 & 314 & 317 & 188 & 188 & 189 & 14,14 & 10,89 & 19,3 \\
7 & 00.00 & 318 & 314 & 317 & 189 & 188 & 188 & 28,5 & 14,7 & 26,5 \\
8 & 01.00 & 312 & 310 & 314 & 185 & 186 & 188 & 28,3 & 14,6 & 26,6 \\
9 & 02.00 & 312 & 312 & 313 & 184 & 185 & 188 & 29,1 & 14,2 & 26,8 \\
10 & 03.00 & 313 & 311 & 313 & 185 & 186 & 187 & 23,5 & 13,3 & 27,2 \\
11 & 04.00 & 312 & 310 & 314 & 184 & 185 & 186 & 23,2 & 13,9 & 26,6 \\
12 & 05.00 & 313 & 311 & 315 & 185 & 186 & 186 & 28,4 & 13,6 & 26,5 \\
\hline
\end{tabular}

Nilai tegangan tiga fasa, tegangan satu fasa, dan nilai arus listrik yang tertinggi di tunjukan pada tabel 4 berada pada jam 18:00 fasa R-S dengan nilai $325 \mathrm{~V}$, di jam 18:00 fasa R-N dengan nilai $194 \mathrm{~V}$, dan di jam 2:00 fasa $R$ dengan nilai 29,1 A. Untuk nilai tegangan tiga fasa, tegangan satu fasa, dan nilai arus listrik yang terrendah di tunjukan pada tabel 4 berada pada jam 1:00 dan 4:00 fasa R-T dengan nilai $310 \mathrm{~V}$, di jam 2:00 dan 4:00 fasa R-N dengan nilai $184 \mathrm{~V}$, dan di jam 19:00 fasa $\mathrm{R}$ dengan nilai 8,73 A.

Tabel 5. Pengukuran Tegangan dan Arus Listrik 10 Maret 2021.

\begin{tabular}{ccccccccccc}
\hline \multirow{2}{*}{ No } & Waktu & \multicolumn{4}{c}{ Tegangan Listrik (Volt ) } & \multicolumn{3}{c}{ Arus Listrik (Ampere) } \\
\cline { 3 - 11 } & & $\mathbf{R}-\mathbf{S}$ & $\mathbf{R}-\mathbf{T}$ & $\mathbf{S}-\mathbf{T}$ & $\mathbf{R}-\mathbf{N}$ & $\mathbf{S - N}$ & $\mathbf{T}-\mathbf{N}$ & $\mathbf{R}$ & $\mathbf{S}$ & $\mathbf{T}$ \\
\hline 1 & 18.00 & 312 & 311 & 313 & 186 & 185 & 186 & 13,15 & 10,56 & 16,58 \\
2 & 19.00 & 312 & 312 & 313 & 186 & 185 & 186 & 13,18 & 10,66 & 16,86 \\
3 & 20.00 & 311 & 309 & 311 & 185 & 185 & 185 & 13,62 & 10,62 & 16,63 \\
4 & 21.00 & 312 & 310 & 311 & 185 & 184 & 185 & 14,3 & 10,73 & 19,4 \\
5 & 22.00 & 318 & 314 & 317 & 189 & 189 & 190 & 13,94 & 10,93 & 19,3 \\
6 & 23.00 & 318 & 314 & 317 & 181 & 186 & 191 & 14,14 & 10,89 & 19,3 \\
\hline
\end{tabular}




\begin{tabular}{ccccccccccc}
\hline \multirow{2}{*}{ No } & Waktu & \multicolumn{4}{c}{ Tegangan Listrik (Volt ) } & \multicolumn{4}{c}{ Arus Listrik (Ampere) } \\
\cline { 3 - 11 } & & $\mathbf{R}-\mathbf{S}$ & $\mathbf{R}-\mathbf{T}$ & $\mathbf{S}-\mathbf{T}$ & $\mathbf{R}-\mathbf{N}$ & $\mathbf{S}-\mathbf{N}$ & $\mathbf{T}-\mathbf{N}$ & $\mathbf{R}$ & $\mathbf{S}$ & $\mathbf{T}$ \\
\hline 7 & 00.00 & 319 & 314 & 318 & 189 & 186 & 188 & 28,7 & 14,4 & 26,3 \\
8 & 01.00 & 312 & 316 & 314 & 185 & 187 & 188 & 28,2 & 14,2 & 26,21 \\
9 & 02.00 & 312 & 312 & 313 & 186 & 186 & 189 & 29,2 & 14,3 & 26,4 \\
10 & 03.00 & 313 & 311 & 314 & 184 & 186 & 187 & 28,6 & 13,8 & 26,5 \\
11 & 04.00 & 312 & 310 & 314 & 185 & 185 & 186 & 28,4 & 13,9 & 26,6 \\
12 & 05.00 & 313 & 311 & 315 & 185 & 187 & 186 & 28,5 & 13,6 & 26,6 \\
\hline
\end{tabular}

Nilai tegangan tiga fasa, tegangan satu fasa, dan nilai arus listrik yang tertinggi di tunjukan pada tabel 5 berada pada jam 00:00 fasa R-S dengan nilai $319 \mathrm{~V}$, di jam 23:00 fasa R-N dengan nilai $191 \mathrm{~V}$, dan di jam 2:00 fasa $R$ dengan nilai 29,2 A. Untuk nilai tegangan tiga fasa, tegangan satu fasa, dan nilai arus listrik yang terrendah di tunjukan pada tabel 5 berada pada jam 20:00 fasa R-T dengan nilai $309 \mathrm{~V}$, di jam 23:00 fasa R-N dengan nilai $181 \mathrm{~V}$, dan di jam 19:00 fasa R dengan nilai 13,15 A.

Tabel 6. Pengukuran Tegangan dan Arus Listrik 11 Maret 2021.

\begin{tabular}{ccccccccccc}
\multirow{2}{*}{ No } & \multirow{2}{*}{ Waktu } & \multicolumn{4}{c}{ Tegangan Listrik (Volt) } & \multicolumn{4}{c}{ Arus Listrik (Ampere) } \\
\cline { 3 - 10 } & & $\mathbf{R}-\mathbf{S}$ & $\mathbf{R}-\mathbf{T}$ & $\mathbf{S}-\mathbf{T}$ & $\mathbf{R}-\mathbf{N}$ & $\mathbf{S}-\mathbf{N}$ & $\mathbf{T}-\mathbf{N}$ & $\mathbf{R}$ & $\mathbf{S}$ & $\mathbf{T}$ \\
\hline 1 & 18.00 & 320 & 318 & 320 & 193 & 191 & 191 & 10,67 & 10,71 & 12,61 \\
2 & 19.00 & 321 & 318 & 322 & 192 & 191 & 191 & 10,68 & 10,72 & 12,82 \\
3 & 20.00 & 320 & 318 & 320 & 191 & 190 & 192 & 10,65 & 10,73 & 12,81 \\
4 & 21.00 & 320 & 318 & 321 & 192 & 190 & 191 & 13,66 & 10,71 & 16,83 \\
5 & 22.00 & 318 & 314 & 318 & 189 & 190 & 192 & 13,99 & 10,93 & 16,24 \\
6 & 23.00 & 318 & 315 & 318 & 182 & 190 & 192 & 14,02 & 10,84 & 16,25 \\
7 & 00.00 & 317 & 316 & 317 & 188 & 189 & 188 & 27,8 & 13,9 & 26,33 \\
8 & 01.00 & 312 & 310 & 314 & 185 & 186 & 188 & 28,5 & 14,8 & 26,5 \\
9 & 02.00 & 312 & 311 & 312 & 184 & 185 & 188 & 29,1 & 14,5 & 26,8 \\
10 & 03.00 & 313 & 311 & 312 & 185 & 185 & 188 & 29,2 & 13,8 & 26,9 \\
11 & 04.00 & 313 & 310 & 312 & 186 & 186 & 187 & 28,7 & 13,8 & 27,2 \\
12 & 05.00 & 312 & 310 & 311 & 185 & 185 & 187 & 28,6 & 13,6 & 27,3 \\
\hline
\end{tabular}

Nilai tegangan tiga fasa, tegangan satu fasa, dan nilai arus listrik yang tertinggi di tunjukan pada tabel 6 berada pada jam 19:00 fasa S-T dengan nilai $322 \mathrm{~V}$, di jam 18:00 fasa R-N dengan nilai $193 \mathrm{~V}$, dan di jam 3:00 fasa $R$ dengan nilai 29,2 A. Untuk nilai tegangan tiga fasa, tegangan satu fasa, dan nilai arus listrik yang terrendah di tunjukan pada tabel 6 berada pada jam 1:00, 2:00, dan 4:00 fasa R-T dengan nilai $310 \mathrm{~V}$, di jam 2:00 fasa R-N dengan nilai $184 \mathrm{~V}$, dan di jam 20:00 fasa R dengan nilai 10,65 A.

Nllai Efisinsi Generator terhadap profil daya semu dapat di tentukan dengan Rumus persamaan 6. Dimana, nilai yang di tentukan dari rata rata nilai tegangan (Volt) dan rata rata nilai arus listrik (Ampere) dalam pemakaian beban listrik atau pada table profil harian pengukuran listrik. Berikut data penentuan nilai efisiensi generator terhadap profil daya semu pada jam 18:00 tanggal 09 Maret 2021, dengan perhitungan persamaan 6 berikut:

$S=\sqrt{ } 3 . \mathrm{V} . \mathrm{I}$

$$
=\sqrt{ } 3 \times 323,33 \times 12,14=6,80 \mathrm{kVA}
$$




$$
\begin{aligned}
\text { Efisiensi }\left(\eta_{\mathrm{G}}\right) & =\frac{\text { Daya Guna }}{\text { Daya Total }} \times 100 \% \\
& =\frac{6,80}{62,5} \times 100 \%=10,88 \%
\end{aligned}
$$

Jadi, pada pukul 18:00 tanggal 09 Maret 2021 pemakaian beban daya semu terhitung 6,80 kVA. Dengan efisiensi Generator $10,88 \%$. Untuk, perhitungan selanjutnya dala waktu yang di tentukan dapat di lihat pada tabel dan gambar diagram berikut:

Tabel 7. Nilai Daya Semu dan Nilai Efisiensi 09 Maret 2021.

\begin{tabular}{cccccc} 
No & Waktu & $\begin{array}{c}\text { Tenganan } \\
\boldsymbol{x}\end{array}$ & $\begin{array}{c}\text { Arus Listrik } \\
\boldsymbol{x}\end{array}$ & $\begin{array}{c}\text { Rumus Persamaan } \\
(\mathbf{4})(\mathbf{k V A})\end{array}$ & $\begin{array}{c}\text { Rumus Persamaan } \\
(\mathbf{6})(\%)\end{array}$ \\
\hline 1 & $18: 00$ & 323,33 & 12,14 & 6,78 & 10,88 \\
2 & $19: 00$ & 321,67 & 12,10 & 6,74 & 10,78 \\
3 & $20: 00$ & 317,33 & 12,65 & 6,96 & 11,13 \\
4 & $21: 00$ & 315 & 14,83 & 8,09 & 12,95 \\
5 & $22: 00$ & 315,67 & 14,74 & 8,06 & 12,90 \\
6 & $23: 00$ & 316,33 & 14,78 & 8,1 & 12,95 \\
7 & 00.00 & 316,33 & 23,23 & 12,73 & 20,37 \\
8 & $1: 00$ & 312 & 23,17 & 12,52 & 20,03 \\
9 & $2: 00$ & 312,33 & 23,37 & 12,64 & 20,23 \\
10 & $3: 00$ & 312,33 & 21,33 & 11,54 & 18,47 \\
11 & $4: 00$ & 312 & 21,23 & 11,48 & 18,36 \\
12 & $5: 00$ & 313 & 22,83 & 12,8 & 19,81 \\
\hline
\end{tabular}

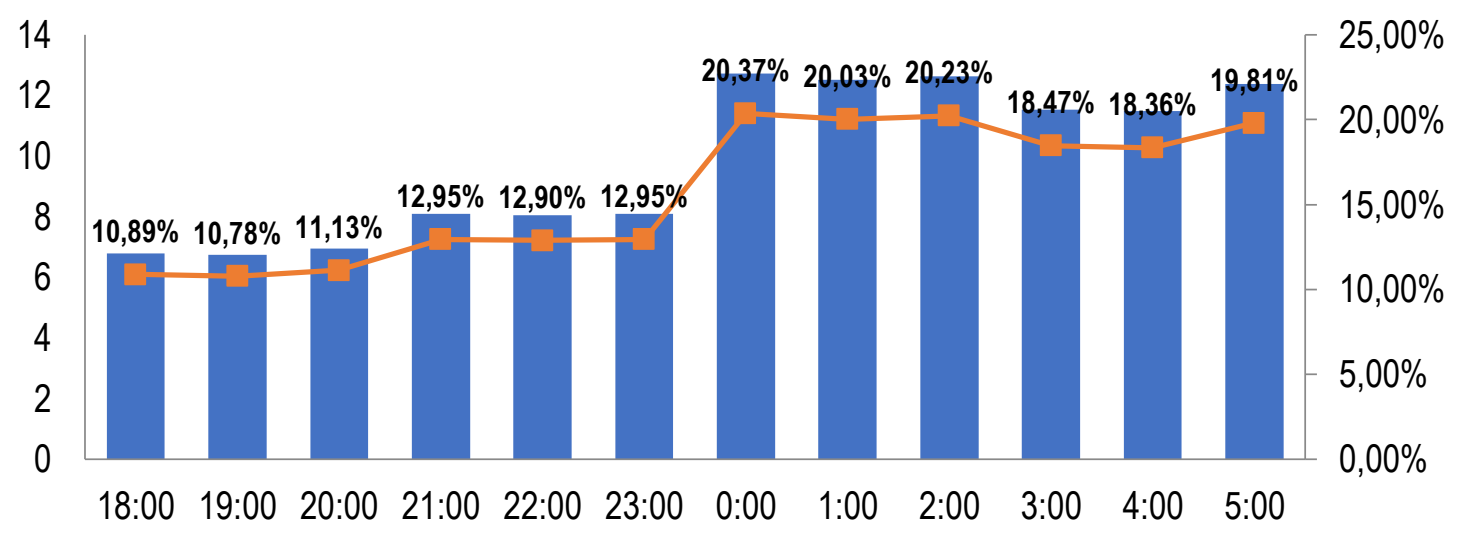

Daya Semu (kVa) -Efisiensi Generator (\%)

\section{Gambar 2. Nilai Daya Semu dan Nilai Efisiensi 09 Maret 2021.}

Tabel 7 dan Gambar 2 menunjukan kondisi perhitungan daya semu dan efisiensi penggunaan Generator pada tanggal 09 Maret 2021. Dimana, dari jam 20:00 sampai dengan jam 21:00. terdapat peningkatan dengan selisih $11,13 \%$ dan $12,95 \%$ dikarenakan penggunaan lampu Halogen bertambah yang menyebabkan pengukuran tegangan dan arus berubah sehingga mempengaruhi nilai daya semu dan efisiensi pengguna an Generator. Dalam hal ini, lampu Halogen yang di fugsikan sebagai pemikat ikan, sehingga target ikan yang bergerombolan agar tidak lari dikarenakan ikan pemangsa seperti ikan lumba-lumba. Hal tersebut menyebabkan mengganggu keberadaan ikan yang bergerombolan berada di 
bawah kapal atau di posisi cahaya dekat kapal dari lampu Halogen. Maka dari itu, penyalaan lampu Halogen di lakukan peningkatan perlahan atau tidak di nyalakan sekaligus. Peningkatan yang signifikan terjadi pada jam 23:00 sampai dengan 00:00 dengan selisih 12,95 \% dan 20,37\% disebabkan oleh faktor dari persiapan pengoperasian alat tangkap.

Tabel 8 gambar 3 dan tabel 9 gambar 4 juga menunjukan kondisi peningtatan atau penurunan daya semu dan efisiensi penggunaan Generator KM. Pulau Pinang yang di pengaruhi oleh penggunaan beban kelistrikan dan juga dinyatakan dengan kondisi yang sama pada Tabel 7 dan Gambar 2.

Tabel 8. Nilai Daya Semu dan Nilai Efisiensi 10 Maret 2021.

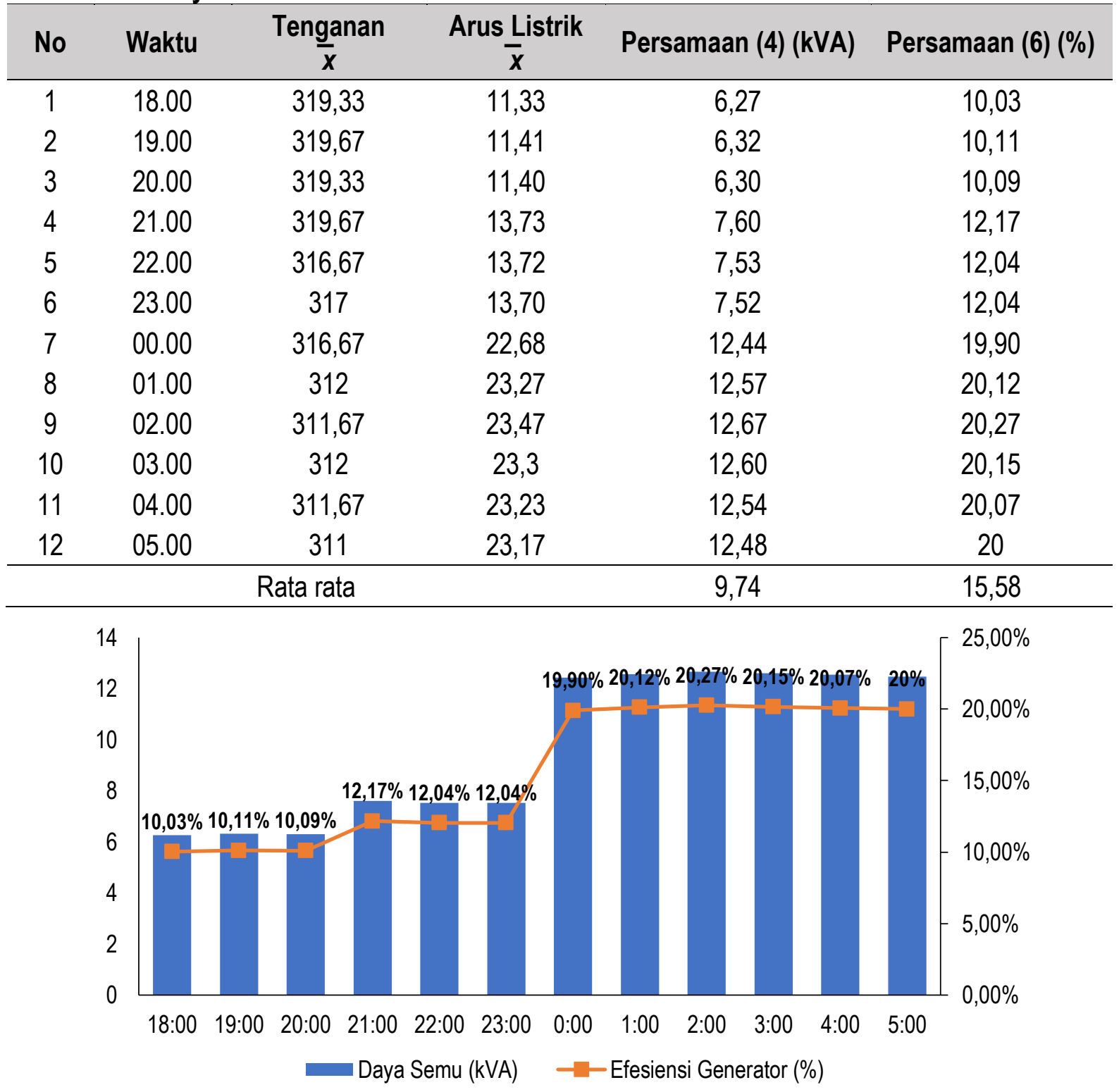

Gambar 3. Nilai Daya Semu dan Nilai Efisiensi 10 Maret 2021.

Tabel 9. Nilai Daya Semu dan Nilai Efisiensi 11 Maret 2021.

\begin{tabular}{cccccc}
\hline No & Waktu & $\begin{array}{c}\text { Tenganan } \\
\boldsymbol{x}\end{array}$ & $\begin{array}{c}\text { Arus Listrik } \\
\overline{\boldsymbol{x}}\end{array}$ & Persamaan (4) (kVA) & Persamaan (6) (\%) \\
\hline 1 & 18.00 & 312 & 13,43 & 7,26 & 11,61 \\
2 & 19.00 & 312,33 & 13,57 & 7,34 & 11,74 \\
\hline
\end{tabular}




\begin{tabular}{cccccc}
\hline No & Waktu & $\begin{array}{c}\text { Tenganan } \\
\mathbf{x}\end{array}$ & $\begin{array}{c}\text { Arus Listrik } \\
\overline{\boldsymbol{x}}\end{array}$ & Persamaan (4) (kVA) & Persamaan (6) (\%) \\
\hline 3 & 20.00 & 310,33 & 13,62 & 7,32 & 11,72 \\
4 & 21.00 & 311 & 14,81 & 7,98 & 12,76 \\
5 & 22.00 & 316,33 & 14,72 & 8,07 & 12,91 \\
6 & 23.00 & 316,33 & 14,78 & 8,10 & 12,95 \\
7 & 00.00 & 316,33 & 23,13 & 12,68 & 20,28 \\
8 & 01.00 & 314 & 22,87 & 12,44 & 19,90 \\
9 & 02.00 & 312,33 & 23,3 & 12,61 & 20,17 \\
10 & 03.00 & 312,67 & 22,97 & 12,44 & 19,90 \\
11 & 04.00 & 312 & 22,97 & 12,41 & 19,86 \\
12 & 05.00 & 313 & 22,9 & 12,41 & 19,86 \\
\hline \multicolumn{7}{c}{ Rata rata } & & 10,09 & 16,14
\end{tabular}

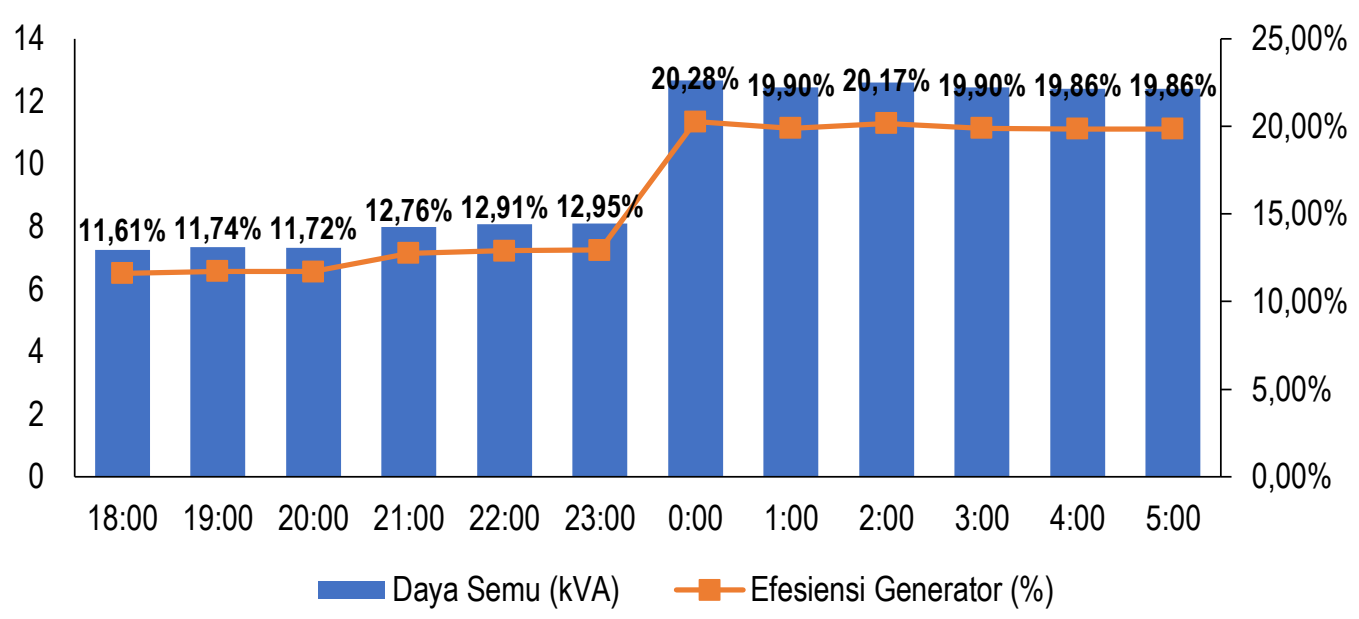

\section{Gambar 4. Nilai Daya Semu dan Nilai Efisiensi 11 Maret 2021.}

Nilai rata rata daya semu tertinggi pada Tabel 7 Gambar 2, Tabel 8 Gambar 3, dan tabel 9 gambar 4 yaitu $12,73 \mathrm{VA}, 12,67 \mathrm{VA}$, dan 12,68 VA, dan di dapat nilai efisiensi tiap tiap nilai rata rata tertinggi pada tabel 7 , tabel 8 , dan tabel 9 yaitu $20,4 \%, 20,3 \%$, dan $20,3 \%$.

Berikut perbandingan nilai Daya semu tertinggi dan nilai rata rata Efisiensi tertinggi dalam penggunaan Generator Set:

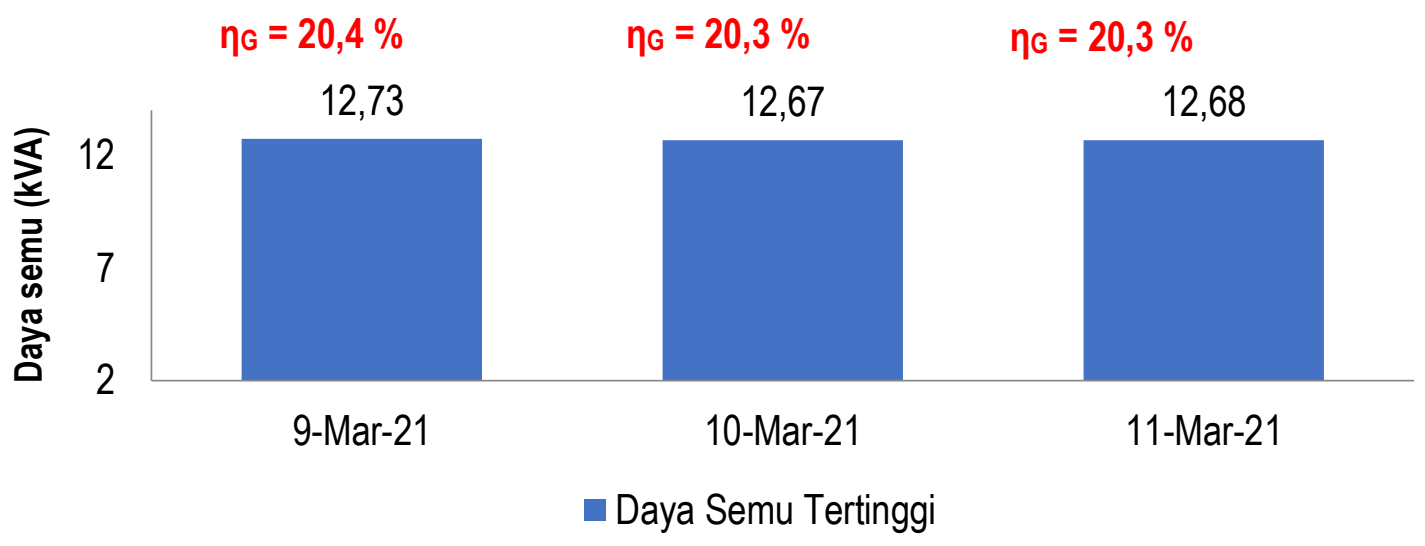

Gambar 5. Grafik Profil Nilai Daya Semu Tertinggi dan Efisiensi Tertinggi. 


\subsection{Identifiksi Putaran Mesin Penggerak Generator di KM. Pulau Pinang}

Pengaruh putaran mesin penggerak Generator berhubungan dengan nilai tegangan dan frekuensi. Dimana, spesifikasi Generator KM. Pulau Pinang menunjukan nilai tegangan 400 Volt pada frekuensi 50 $\mathrm{Hz}$. Dengan demikian rasio tegangan per frekuensi di atur ke nilai konstan $(400 / 50=8 \mathrm{~V} / \mathrm{Hz})$. Spesifikasi Generator menunjukan rpm maksimal $1.500 \mathrm{rpm}$ dan frekuensi $50 \mathrm{~Hz}$ maka di dapat jumlah kutup yaitu 4. Dari rasio tengangan per frekuensi dapat di tentukan nilai kecepatan putaran (rpm) mesin penggerak Generator pada setiap waktu pengoperasian mesin listrik KM. Pulau Pinang. Berikut nilai rpm pada jam 18:00 tanggal 09 Maret 2021 dengan tegangan rata rata 323,33 V:

$$
\begin{array}{rlrl}
\text { Rasio V/Hz } & =8 & \text { Ns } & =\frac{120 \times 40,4}{4} \\
\text { Frekuensi } & =\frac{V}{8} & & =1.212,5 \mathrm{rpm} \\
& =\frac{323,33}{8}=40,4 \mathrm{~Hz} &
\end{array}
$$

Nilai kecepatan mesin penggerak Generator rpm pada jam 18:00 tanggal 09 Maret 202 di dapat 1.212 rpm. Maka dari itu, nilai rpm dari jam 18:00 sampai dengan 05:00 pada tanggal 09 Maret 2021 dapat di lihat dari tabel berikut:

Tabel 10. Rpm Motor Penggerak Generator Tanggal 09 Maret 2021.

\begin{tabular}{cccccc} 
No & Waktu & $\begin{array}{c}\text { Tenganan } \\
\boldsymbol{x}\end{array}$ & Rasio V/Hz & Frekuensi (Hz) & rpm \\
\hline 1 & $18: 00$ & 323,33 & 8 & 40,4 & $1.212,5$ \\
2 & $19: 00$ & 321,67 & 8 & 40,2 & $1.206,3$ \\
3 & $20: 00$ & 317,33 & 8 & 39,7 & $1.190,0$ \\
4 & $21: 00$ & 315 & 8 & 39,4 & $1.181,3$ \\
5 & $22: 00$ & 315,67 & 8 & 39,5 & $1.183,8$ \\
6 & $23: 00$ & 316,33 & 8 & 39,5 & $1.186,2$ \\
7 & 00.00 & 316,33 & 8 & 39,5 & $1.186,2$ \\
8 & $1: 00$ & 312 & 8 & 39,0 & $1.170,0$ \\
9 & $2: 00$ & 312,33 & 8 & 39,0 & $1.171,2$ \\
10 & $3: 00$ & 312,33 & 8 & 39,0 & $1.171,2$ \\
11 & $4: 00$ & 312 & 8 & 39,0 & $1.170,0$ \\
12 & $5: 00$ & 313 & 8 & 39,1 & $1.173,8$ \\
\hline
\end{tabular}

Spesifik mesin penggerak generotor pada KM. Pulau Pinang adalah 2.800 rpm. Dari tabel 11 nilai rpm tertinggi adalah $1.212 \mathrm{rpm}$. Maka dari itu penggunaan mesin penggerak Generator pada KM. Pulau Pinang di asumsikan memenuhi ketentuan rpm dari Generator. Terbukti bahwa rpm pengoperasian mesin listrik pada waktu pemakaian dari jam 18:00 sampai dengan 05:00 tanggal 09 Maret 2021 dapat di simpulkan lebih kecil dari rpm spesifikasi mesin penggerak Generator. Dengan catatan rpm mesin penggerak Generator tidak melebihi spesifikasi rpm Generator (2.800 rpm $\leq 1.500 \mathrm{rpm}$ ). Hal tersebut di antisifasi dengan cara mengatur rpm mesin penggerak Generator dengan catatan melepas beban listrik dan melihat indikator Voltmeter dan Frekuensi meter di posisi jarum tidak lebih dari 400 Volt dan $50 \mathrm{~Hz}$. Hal tersebut bertujuan agar tidak terjadi kerusakan pada beban komponen listrik secara keseluruhan. 


\section{Kesimpulan}

Nilai efisiensi penggunaan Generator terhadap pengukuran daya semu (VA), di KM. Pulau Pinangyaitu dengan nilai rata rata daya semu tertinggi pada tabel 7 gambar 2, tabel 8 gambar 3 , dan tabel 9 gambar 4 yaitu 12,73 VA, 12,67 VA, dan 12,68 VA, dan di dapat nilai efisiensi tiap tiap nilai rata rata tertinggi pada tabel 7, tabel 8 , dan tabel 9 yaitu $20,4 \%, 20,3 \%$, dan $20,3 \%$. Nilai efisiensi terhadap daya aktif (Watt) terhitung adalah 42,142\%. Dari nilai tersebut perbandingan kapasitas daya Generator pada KM. Pulau Pinang dan pemakaian daya listrik Generator KM. Pulau Pinang terbilang tidak efisien. Karena, efesiesi yang baik terhitung pada nilai terendah $78 \%$ dan atantara sampai dengan tertinggi $100 \%$. Oleh karena itu, di rekomendasikan kapasitas Generator 30 kVA. Untuk kecepatan putaran mesin penggerak Generator pada KM. Pulau Pinang sudah di kategorikan sesuai. Dimana, Terbukti bahwa rpm pengoperasian mesin listrik pada waktu pemakaian dari jam 18:00 sampai dengan 05:00 tanggal 09 Maret 2021 dapat di simpulkan lebih kecil dari rpm spesifikasi mesin penggerak generator. Dengan catatan rpm mesin penggerak generator tidak melebihi spesifikasi rpm generator $(2.800 \mathrm{rpm} \leq 1.500$ rpm).

\section{Daftar Pustaka}

Arifin, I., \& Rangga, M. (2018). Analisa Efisiensi dan Rancangan Generator Permanent Magnet 12 Slot 8 Pole Menggunakan Software Magnet 7.5. SMAP, 43-47.

Azhar, Syaipul;. (2020). Desain Turbin Pembangkit Listrik Energi Pasang Surut Di Wilayah Perairan Desa Bagan Siapi-Api Kecamatan Rokan Hilir Riau. Riau: Universitas Riau.

Nahar, M. (2010). Pengaturan Level Ketinggian Air Berbasis Inverter Drive LG-SV008iC5. Jakarta: Universitas Indonesia.

Nur, I. R., Farid, A., \& Apri Arisandi. (2009). Efektivitas Alat Tangkap Mini Purse Seine Menggunakan Sumber Cahaya Berbeda Terhadap Hasil Tangkapan Ikan Kembung. Kelautan, II, 50-59.

Peri, Riki Ramadani;.. (2020). Analisa Perhitungan Beban Kelistrikan Generator KM. Maradona, Sibolga, Sumatera Utara. Politeknik KP Dumai. Dumai: Politeknik KP Dumai.

Purwa, Anjaya Wiyastra; S, Mulyono Baskoro; Purwangka, Fis;. (2012). Instalasi Permesinan Pada Kapal PSP 01. Teknologi Perikanan dan Kelautan, 35-43.

Razak, Abdul; Firdaus;. (2018). Analisa Teknis Instalasi Kelistrikan Kapal Motor Penumpang Swarna Putri. Jom FREJNIK, 5(2), 1-6.

Reise, P. (2012). Manual of Power Factor Correction. Frako: Teningen.

SNI 0225:2011. (2011). Persyaratan Umum Istalasi Listrik (PUIL). BSN.

Suman, Ali; Wudianto; Sumiono, Bambang; Eko, Hari Irianto; Badrudin; Amri, Khairul;. (2014). Potensi Dan Tingkat Pemanfaatan Sumberdaya Ikan Di Wilayah Pengelolaan Perikanan Republik Indonesia (WPR RI). Jakarta, Ref Graphika.

Weedy, B. M., Cory, B. J., Jenkins, N., Ekanayake, J. B., \& Strbac, G. (2012). Electric Power Sytem. Inggris: Jhond Wiley \& Sons Ltd. 